\title{
Virtue Ethics and Moral Psychology: The Situationism Debate
}

\author{
Candace L. Upton
}

Published online: 27 May 2009

(C) Springer Science+Business Media B.V. 2009

Aristotle was acutely aware of the importance of moral psychological observations to virtue ethics. In his brief discussion of bravery in the Nicomachean Ethics, he makes at least ten explicit empirical claims about the actual psychological states and abilities of moral agents (Aristotle 1985). His psychological observations concern the limits beyond which human beings cannot control their behavior, sanity and the capacity for emotional response, motivation, fear, self-esteem, anger and revenge, false belief and hopefulness, the false beliefs of the less-than-virtuous about their own emotional responses and physical abilities, the relative difficulties of exacting self-control, and the emotional response of humans to pains and difficulties. ${ }^{1}$ The other virtues Aristotle enumerates and characterizes, from generosity and justice to truthfulness and shame, are similarly laden with empirical observations about human behavior, reason, emotion, and capabilities.

\footnotetext{
${ }^{1}$ A selection of Aristotle's claims about the moral psychological states related to bravery follow: "Some things are too frightening for a human being [with any sense] to resist." 1115b7-1115b9; "He would be some sort of madman, or incapable of feeling distress, if he feared nothing..." $1115 \mathrm{~b} 25-1115 \mathrm{~b} 27$; "...rash people are impetuous, and wish for dangers before they arrive, but shrink from them when they come..." 1116a7-1116a9; "citizens seem to stand firm against dangers with the aim of avoiding reproaches and legal penalties and winning hours..." 1116a19-1116a20; "the professional [soldiers at the incident at the temple of Hermes] from the start were facing the danger on the assumption of their superiority, and once they learn their mistake, they run, since they are more afraid of being killed than of doing something shameful..." 1116b20-1116b23; "Human beings...find it painful to be angered, and pleasant to exact a penalty." $1117 \mathrm{a} 5$; "...the hopeful are confident because they think they are stronger and nothing could happen to them - and drunks do the same sort of thing, since they become hopeful." 1117a9-1117a15; "Those who act in ignorance also appear brave, and indeed they are close to hopeful people, though inferior to them insofar as they lack hopeful people's self-esteem." 1117a24-1117a25; "...it is harder to stand firm against something painful than to refrain from something pleasant." 1117a35; "boxers find that the end they aim at, the crown and the honours, is pleasant, but being made of flesh, they find it distressing and painful to take the punches and to bear all the hard work..." 1117b3-1117b7.
}

C. L. Upton $(\bowtie)$

Department of Philosophy, University of Denver, 2000 E. Asbury Ave, Denver, CO 80208, USA e-mail: cupton@du.edu 
The body of Aristotle's moral psychological claims about human beings leads him, along with a complex set of philosophical claims and outright assertions, in some cases, to develop his account of virtue. The core of this account holds that to possess a virtue, $\mathrm{V}$, an individual must (i) embody a range of conative and cognitive states and processes that are stable and appropriate to V; (ii) respond appropriately to situations that are relevant to $\mathrm{V}$, either behaviorally or attitudinally, such that $\mathrm{V}$-appropriate responses issue from the $\mathrm{V}$-appropriate mental states; and (iii) respond appropriately across a broad range of $\mathrm{V}$-appropriate kinds of situation. For example, an honest person should care about truthfulness, desire to be honest and to sustain her healthy relationships, reason appropriately about why she should tell the truth, know when to tell the truth, summon her willpower when needed to tell the truth in trying situations, feel sadness or dismay when she encounters others who are not truthful, and feel pleasure when she behaves honestly. Second, the honest person should behave honestly, or at least she should display appropriate emotional responses if she is unable to behave honestly. And, finally, the honest person should respond appropriately to all kinds of honesty-relevant situations she encounters; that is, her honesty should be cross-situational, or global. She should respond appropriately if she is tempted by another to cheat or steal, if she encounters an opportunity to distort information, and she should respond appropriately to friends, family, strangers, and so on.

Aristotle's compendium of moral psychological claims was not informed by rigorous, scientific methodology. More likely, the informal annals of Aristotelian moral psychology are the product of several decades' worth of careful observation of, intense discussion of, and honest (and probably, sometimes, painful) rumination over his own and others' behavior, emotions, reasons, and mistakes. Despite the pretheoretical process that probably begat Aristotle's moral psychology, his views about human nature and human behavior are, with some exceptions, particularly those concerning women and slaves, mature, insightful, and intuitive, and are tenably recognized as such by mature, insightful, and intuitive human beings. And the virtue theory which goes hand in hand with his moral psychology, even if not always countenanced in its every detail, has assuredly achieved its historical and philosophical prominence because of its subtlety, complexity, and plausibility. For these reasons, it does not overstep the bounds of reasonableness to conclude that the more rigorously-produced moral psychological observations generated by social psychologists of the 20th and 21st centuries would augment the plausibility and power of not only Aristotelian virtue theory but also virtue theories and virtue ethical approaches that diverge from the Aristotelian paradigm.

But, rather than enhancing virtue ethics, contemporary social psychology, as understood by a handful of moral philosophers, undermines virtue ethics. Situationism is the empirical thesis, supported by the research of several hundred social psychologists, that variance in human behavior is typically a function of the situation a person inhabits, or takes herself to inhabit, rather than any traits of character she putatively possesses. Articulated in epistemic terms, situationism claims that the situation a human being inhabits, or takes herself to inhabit, better predicts and explains her behavior than her putative traits of character. Typically, the situational change introduced in situationist experiments is seemingly both 
morally and motivationally innocuous but, yet, produces morally inappropriate, dubious, or even appalling behavior from its subjects. ${ }^{2,3}$

Three social psychological experiments figure prominently in the analytic philosophical treatment of situationism. S. Milgram's Obedience Experiment, P. Zimbardo's Stanford Prison Experiment, and J. Darley and C. Batson's Princeton Theological Seminary Experiment are all notable not only for their methodological rigor, but also for the morally disturbing behavior their subjects display (Milgram 1974; Haney et al. 1973; Darley and Batson 1973). Milgram's well-known and frequently-cited Obedience Experiment concerns the human tendency to obey authority and the factors that seemingly reinforce this tendency. Milgram solicited subjects for his experiments by placing an ad in a local newspaper, which drew subjects from a diverse range of age- and gender-related, educational, socioeconomic, and cultural groups. Milgram encouraged each subject electrically to shock another participant in the experiments (actually a confederate of Milgram's pretending to experience pain from faux shocks) with a series of thirty shocks, each shock increasing incrementally in intensity, every time the other participant failed accurately to recall a word pair. Milgram encouraged the subjects to apply the shocks simply by firmly uttering a series of verbal provocations, which included "Please continue," "The experiment requires that you continue," "It is absolutely essential that you continue," and "You have no other choice, you must go on." The participant who was receiving the faux shocks, after screaming in pretend agony after being shocked with 330 volts, feigned unconsciousness but, yet, two-thirds of the subjects continued to shock the other participant eight more times, up to 450 volts. The subjects' broad demographic distribution precludes any likelihood that Milgram attracted a group of psychopaths, or other individuals who antecedently possessed a tendency to inflict cruel behavior, as subjects. The only plausible explanation of the subjects' behavior, according to situationists, is the nature of the situation (and its impact on complex personality features), which included an authority figure prompting them to shock another human being.

Like Milgram's Obedience Experiment, Zimbardo's Prison Experiment focuses on harming behavior. Zimbardo chose twenty-one college-age males for the experiment. The males volunteered to be experimental subjects, but were selected on the basis of the hallmarks of sound mental health which they all exhibited. The males were randomly assigned to play either the role of guard or the role of prisoner in a basement wing of Stanford University, where the wing's rooms were set up to function as prison cells. The "guards" were given a brief list of general rules to follow, which would guide their guard-like behavior, and the "prisoners" were told only that they must follow the guards' rules. On the morning of the second day, a power struggle erupted between the prisoners and guards; the guards responded by spraying the prisoners with a fire extinguisher, stripping the prisoners naked, and forcing the ringleaders into solitary confinement. The struggle escalated to the point where guards forced the prisoners to engage in a series of increasingly cruel and

\footnotetext{
2 J. Sabini and M. Silver point out these features of situationist experiments, along with several other distinctive and typically unnoticed putative features. See Sabini and Silver (2005).

${ }^{3}$ For extensive reviews of situationist literature, see Ross and Nisbett (1991) and Doris (2002, Chap. 3).
} 
degrading punishments, which included smearing food in the prisoners' faces, forcing the prisoners to play nearly-naked leapfrog, and forcing the prisoners to clean toilets with their bare hands. An outside observer, astonished by the guards' behavior and the prisoners' traumatized reactions, encouraged Zimbardo to terminate the experiment after only 6 days of its planned 2 week length. Afterwards, several of the guards confessed to both their genuine and intense frustration and anger with the prisoners' behavior and also to their satisfaction gained from punishing the prisoners. The guards, who displayed no detectable signs of psychopathy, any other psychological malady, or even any tendency to behave so cruelly (one guard claimed prior to the experiment that he was a pacifist), nonetheless, engaged in brutish and vile behavior; the only explanation for their behavior seems to be the nature of the situation they inhabited.

Focusing on helping behavior, Darley and Batson asked students of Princeton's Theological Seminary to deliver a speech on the Biblical figure, the Good Samaritan, who willingly helped others when no one else would. One-third of the students were told that they must hurry to a different building to deliver their talk, one-third were told that they were right on time to deliver their talk, and one-third were told that they had plenty of time to reach their destination. On their walk to the speech site, each student encountered a confederate of the experimenter who appeared to need the student's help, being in some kind of physical distress. Sixtythree percent of students who were early helped the confederate, but only $45 \%$ of students who were on time helped, while a paltry $10 \%$ of students who were in a hurry helped. Absent any features of character that might explain the covariance of helping behavior and degree of hurry, situationists concluded that the seminarians' behavior was engineered by the situation, not by their pre-existing internal mental states or traits of character. ${ }^{4}$

A vast collection of social psychological experiments leads to the situationist's conclusion. For example, human helping behavior is highly correlated with factors such as pleasant weather, noise level, familiarity with a potential victim, and nonurban origins. ${ }^{5}$ Human beings are much more likely to help others in the presence of sunshine, moderate temperatures, and low wind velocity, in the absence of loud, grating noises, when they have personally met a potential theft victim, and if the potential helper was raised in a rural environment. ${ }^{6}$

So how, exactly, is situationism relevant to virtue ethics? After all, even introductory students of ethics should be sufficiently familiar with the normative/ descriptive distinction to note that no mere empirical fact about the actual condition of the world or its inhabitants can alone, without argumentative supplementation,

\footnotetext{
${ }^{4}$ For recent psychological discussion of the Shocking, Prison, and Seminary experiments, see: Blass (1996, 2004); Darley (1995); Doris and Murphy (2007); Elms (1995); Goldhagen (1996); Haney and Zimbardo (1998); Lutsky (1995); Meeus and Raaijmakers (1995); Miller (1995); Modigliani and Rochat (1995); Rochat and Modigliani (1995); Rosenthal (1999); and Zimbardo (2007).

5 See Cunningham (1979); Mathews and Cannon (1975); Shaffer et al. (1975); Gelfand et al. (1973).

6 Situationism is not uncontroversial. Contrary to situationists, personologists hold that personological features are a better predictor of human behavior than are situational features. But it is unclear whether there is even a clear-cut distinction between situationists and personologists. See, for example, Kupperman (1991, pp. 165-166).
} 
yield any substantive normative conclusions. In its conspicuous absence, the missing premise that leads from the descriptive (situationism) to the normative (virtue ethics) demands recognition.

The appeal to situationism in discussions of virtue ethics within analytic philosophy emerges in three phases, roughly demarcated by their chronology, content, and degree of development. The first phase of moral philosophers' connecting situationism to virtue ethics includes Kupperman (1991), Badhwar (1996), and Flanagan (1991). ${ }^{7}$ Kupperman details a range of perceptive and prescient observations on moral psychology in general, and situationism in particular (Kupperman 1991, 1st Appendix). His primary thesis holds that lay observations of human behavior and psychology are superior to those of professional observations; lay observation, if tempered appropriately, can produce information that is not only subtle and propitious, but also accurately reflects the actual states and tendencies of humans. Lay observation, Kupperman argues, is preferable to professional observation since professional observation of human morally-tinged behavior is rendered virtually ineffectual by a series of grave methodological, practical, and ethical impediments. Kupperman concludes by praising the methodological rigor and character-related significance of Milgram's Obedience Experiment (Milgram 1963, 1974), and claims that similar experiments could hold great promise for the moral philosopher. ${ }^{8}$

Badhwar appeals to anecdotal observational findings, not unlike those uncovered by situationists, to argue that the virtues manifest a limited unity (Badhwar 1996). Aristotle argues that the virtues are unified since each virtue requires practical wisdom, and practical wisdom is a single state that, by its nature, determines what an agent ought to do in every kind of situation she encounters. Hence, a just person will embody practical wisdom, and practical wisdom entails the presence of every other virtue; the virtues are thus unified. Badhwar objects, however, that practical wisdom is not a single state, and human agents can have practical wisdom, which involves right judgment as well as the right emotional responses, in some domains but not others. One agent might be fair in judging others' intellectual achievements but, yet, unfair to people who are down and out; kind to those who are down and out but, yet, unkind to those who have gained intellectual achievements. The virtues which informal observation indicates human beings actually possess are domainspecific. Badhwar concludes that domain-specific virtues are unified: an agent cannot be just to her friends unless she is also kind to, honest to, and courageous towards her friends.

Finally, Flanagan entreats laypersons, psychologists, and moral philosophers to minister to the lessons of situationist psychology (Flanagan 1991, pp. 293-314). After setting forth the particulars of several now well-known situationist experiments, he prudently concludes that situationist research outfits us with several tools morally to embetter ourselves. If we cultivate an awareness of the situational factors

\footnotetext{
7 See also Hurka (2001, p. 44), Blackburn (1998, p. 36), and Railton (1997, pp. 94-95).

8 Ironically, as the perspicacious reader of this collection will note, a number of Kupperman's objections to professional observation of human behavior also apply to the situationist research that many philosophers have taken to undercut virtue ethics. Kupperman is never inconsistent on this point. See Kupperman (2001) and "Virtue in virtue ethics," this issue of The Journal of ethics.
} 
that have a tendency to produce behavior ranging from the morally fiendish to the morally inappropriate, we empower ourselves not only to avoid these kinds of situation, but also to establish and maintain a kind of social life that either precludes these situational factors or cripples their causal efficacy. Flanagan advances his substantive conclusions cautiously. Notably, while he suggests that situationist findings might engender skepticism about the existence of cross-situational traits he concludes that this skepticism is not ultimately warranted.

G. Harman and J. Doris launch the second phase of the situationism debate, whose initial statement has been widely, albeit somewhat inappropriately, dubbed 'the situationist critique of virtue ethics' (Harman 1999, 2000, and Doris 1998, 2002). Both Harman and Doris argue that, properly applied, situationist findings vitiate traditional virtue ethics and also suggest a range of illuminating strategies for moral and social improvement. Harman's and Doris's arguments, while superficially similar, differ importantly in their detail; the second phase of the situationism debate is, hence, best characterized as focusing on the situationist critiques of virtue ethics.

Recall the Aristotelian account of virtue, whose third criterion requires that a virtuous agent behave virtuously across a broad range of different types of situation. A compassionate person would not behave compassionately only to other helpful people, while turning her head to the interests of selfish people; and a kind person would not behave kindly to others only when she is alone, while ignoring the needs of others when she is in a group. Instead, compassionate people and kind people would always behave compassionately or kindly, irrespective of the nature of the situation they inhabit. Situationist research, however, uncovers situation-indexed moral impairments in the behavior of most human beings. Most people would not behave compassionately in the presence of an authority goading them to behave cruelly; most people would not help an obviously ailing individual when they are in a hurry or in a group; and most people would not help another person in the presence of cold temperatures, grating noises, or harsh lighting.

Harman draws three important, albeit, contentious conclusions from situationist findings. First, he argues that the empirical foundation that would substantiate the existence of character traits in most human beings is manifestly absent: if we possessed character traits, our behavior would not covary so highly with the situation. Harman draws the respectively weaker and stronger conclusions that "it may...be the case that there is no such thing as character, no ordinary character traits of the sort people think there are" (Harman 1999, p. 1) and "there is no empirical basis for the existence of character traits" (Harman 1999, p. 1); hence, we must renounce all talk and thought of character. Second, employing his weaker conclusion, Harman argues that if there is no such thing as character, then there is, correspondingly, no thoroughfare that even the most conscientious, adept, and persistent moral agent can tread in the attempt to develop virtuous character traits. Finally, Harman argues that, to cultivate an improved moral life, along with more morally sensitive and effective public and legal policies, the moral agent must strive not to develop her virtue but, rather, to implement situational changes in both the personal and public aspects of her life.

Doris begins by arguing that traditionally-conceived virtue ethics is empirically inadequate. If virtue ethics were empirically adequate, its virtue attributions, such as 
courageous, just, honest, and compassionate, would accurately describe most of the population. However, the traditional virtues require that, say, a compassionate person behave compassionately across a broad range of kinds of situation, while the empirical results that the situationist research yields clearly show that most people would not behave compassionately across a broad range of situations, since most people would not behave compassionately in situations where they clearly should. Hence, virtue ethics is empirically inadequate. Second, Doris argues that situationist research empirically supports the existence, in most of the population, of local traits of character. Most people would behave compassionately when they are not in a hurry; these people are ambling-along-compassionate. Most people would behave compassionately when they are not in a group; these people are not-in-a-groupcompassionate. Similarly, people who would behave honestly only in the presence of an authority figure are authority-figure-present-honest. Local traits of character, Doris claims, are empirically adequate. Third, Doris argues that empirically adequate traits of character are necessary for moral agents appropriately to guide their moral reasoning, choices, and behavior. To use Doris's example, if an agent knows that she is, say, loyal-to-her-husband-only-when-sober, she will wisely reject her romantically-interested colleague's invitation to dinner and drinks. Doris's bottom line is that traditional virtue ethics, since it endorses empirically inadequate global traits of character, should be, if not abandoned altogether, at least conceptually supplemented with a system of empirically adequate local traits of character.

The responses to Harman's and Doris's situationist critiques of virtue ethics, while they differ in their tone, slant, and subtleties and varieties of argumentation, almost univocally converge upon one primary objection: the conception of virtue that Harman and Doris identify as the target of situationism is a simplistic, implausible strawman. Kupperman, G. Sreenivasan, and C. Miller all lodge the same basic challenge to the Harman-Doris situationist critiques. ${ }^{9}$ These moral philosophers, in articulating their critiques of the situationist critiques, distinctively nuance the objection, import additional objections, and present further positive commentary and argumentation; further, the essays that comprise this volume frequently refer back to these arguments. It is, hence, a valuable endeavor to examine their arguments on an individual basis.

Kupperman claims that Harman's arguments target "an excessively simple view of what character is" and make two false assumptions about the nature of character traits (Kupperman 2001, p. 240). First, Harman assumes an extreme view of character, which requires near-perfection and precludes the possibility that a virtuous person might occasionally err. Second, Harman assumes there is one right action appropriate for every virtuous person in the same situation. More sophisticated and plausible views of virtue, however, allow for virtuous people who are not chronically perfect and also recognize that two fully virtuous individuals, given their different goals, temperaments, and histories, might behave differently in the same situation. Kupperman concludes by arguing that character is conceptually indispensable since we often know that certain people are reliably

\footnotetext{
${ }^{9}$ See also Athanassoulis (1999, pp. 215-221); DePaul (2000, pp. 141-157); Kamtekar (2004); Swanton (2003, pp. 30-33); and Annas (2003).
} 
virtuous and since self-ascriptions of virtue are often resolutions as much as they are descriptions, and he argues that character is pragmatically indispensable since it can constrain our behavior and choices in a range of morally vexing situations.

Sreenivasan directs his attack on the situationist critiques by focusing on the H. Hartshorne and M. May honesty experiments, which were conducted in 1982 (Hartshorne and May 1982). In these experiments, young boys were presented the temptations of pocketing loose change and telling small lies, and their behavior was interpreted as a measure of their honesty. Sreenivasan points out that, in these experiments, while many of the subjects pocketed the loose change they encountered, their mode of conceptualizing the situation might have precluded their behavior's falling under the act-description of theft or dishonesty (Sreenivasan 2002). Further, even if the subjects' behavior was appropriately described as dishonest, pocketing loose change is an act that is only peripheral to genuine dishonesty; there are manifestations of dishonesty that are more central to the trait and, so, are better indicators of its presence. Finally, Sreenivasan argues that the experiments were structured in a way that allowed the subjects multiple reasons in support of their behavior: while many subjects lied about whether other boys pocketed the loose change, these subjects might have reasoned that protecting the other boys' interests trumped their reasons for not lying. Hence, Sreenivasan concludes that the 1928 honesty experiments challenge only an implausible conception of character traits, which disregards the subject's conceptualization of the situation she inhabits, which mistakes behavior that is peripheral to a trait as a central indicator of the trait, and which is insensitive to competing reasons that target the behavior in question. Sreenivasan concludes that "virtue theory has a variety of principled grounds for rejecting [this] conception of a character trait" (Sreenivasan 2002, p. 64).

Miller's objections to the situationist critiques echo those of Kupperman (Miller 2003). Miller argues that Harman and Doris assume an overly-strong account of virtue according to which an agent possesses a virtue $\mathrm{V}$ only if she attempts to perform $\mathrm{V}$-relevant behavior in every situation that calls for V-relevant behavior. Further, he argues that Harman and Doris fail to notice that virtue can come in degrees. Subjects of situationist experiments who do not behave virtuously in one situation kind might be plodding along the difficult path towards becoming virtuous and, so, might be partly, though not fully virtuous. And situationist experiments are consistent with weak or moderate possession of character traits. In an important step forward, Miller proceeds to defend an empirically-substantiated modest sketch of global traits in the form of personality networks. A personality network consists of an agent's cognitive, affective, and motivational states about situation kinds, and they are closely intertwined with her personality structure such that they trigger appropriate goals and appropriate behavior. Personality networks, he argues, are uncontroversial within the social psychology literature, and they can function as global traits in a way that satisfies the normative and pragmatic demands of the virtue theorist. ${ }^{10}$

\footnotetext{
${ }^{10}$ Kamtekar responds to the situationist critiques with what may be the most developed and sophisticated defense of virtue ethics to date (Kamtekar 2004). Contributing to the theme that Harman and Doris assume an oversimplified notion of virtue, she argues that "the so-called character traits that the situationist experiments test for are independently functioning dispositions to behave in stereotypical ways, dispositions that are isolated from how people reason... [but] the conception of character in virtue
} 
The bulk of the response to the situationist critiques defends virtue ethics either directly or indirectly by arguing either that virtue ethics is more subtle and sophisticated than its critics assume or that the situationist experiments are not structured to test for the presence of traditionally-conceived virtues. ${ }^{11}$

Several important lessons emanate from the second phase of the situationism debate. The refined understanding of the nature of virtue and virtue ethical reasoning that responses to the situationist critiques highlight carries special importance to the ethicist who seeks to defend virtue-based ethical deliberation, reasoning, and action as a viable alternative to act- and outcome-based approaches

\section{Footnote 10 continued}

ethics is holistic and inclusive of how we reason" (Kamtekar 2004, p. 460). The situationist experiments, she argues, assume that an agent's possessing a virtue licenses the expectation that she will always, spontaneously and unreflectively, produce trait-characteristic behavior in every situation she encounters. But if a virtuous agent were always to behave altruistically, she would have to abandon her own projects and pursuits, and she might even have to abandon her attempt to help one person if another needy person came along. Kamtekar also notes that the situationist experiments fail to mention anything about subjects' feelings about their actions, which might bear on their possession of the relevant virtue and, paralleling Sreenivasan's argument, she notes that situationist experimenters assume that one objective description of the situation announces itself to both experimenter and subject, failing to account for the possibility that many subjects construe the situation differently, hence explaining why seemingly virtuous people behave in seemingly unvirtuous ways. Further, she suggests that the virtues endorsed by virtue ethicists might fare better conceived narrowly. While the stereotypical conception of honesty requires telling the truth, not cheating, and not lying, situationist experiments hint that virtue ethicists ought to conceive of traits narrowly. Instead of endorsing traits like honesty, perhaps we should endorse traits like honest-withrespect-to-property since situationist findings suggest there is no reason to expect inter-situationally consistent behavior in some cases.

${ }^{11}$ Two interesting and valuable responders, however, instead of defending virtue ethics against the critiques, argue that situationist findings challenge two additional views associated with virtue ethics. These arguments, defended by M. Merritt and P. Vranas can, thus, be construed as two additional situationist critiques of virtue ethics.

First, Merritt, rather than focusing on the seemingly morally inappropriate behavior produced in a number of the situationist experiments, focuses on the seemingly appropriate behavior produced (Merritt 2000). According to situationism, human behavior covaries with the situation. It follows, then, that not only morally bad or inappropriate behavior, but also morally good or appropriate human behavior covaries with the situation; good human behavior is socially-sustained. As Merritt puts the point: "our own ethical character [is] dependent...upon our involvements in social life" (Merritt 2000, p. 374). But, traditional virtue ethics holds that the virtues should be self-sufficient, that we should aim to develop virtues that issue in virtuous behavior irrespective of the situation; our virtues should be seeds that flower in virtuous behavior no matter the soil, lighting, or water conditions. Merritt defends the sociallysustained conception of character traits by arguing that, in developing self-sufficient traits of character, agents would have to extract themselves from the most important aspects of their lives as social beings and also neglect the various goods and evils to which moral agents are supposed to be sensitive. Developing traditional, self-sufficient, virtues would hence be socially and personally injurious, as well as morally irresponsible, perhaps even crossing the bounds of sanity.

Second, Vranas rigorously defends the metaphysical conclusion that it makes no sense to talk about the traditionally-understood character status of human agents since most humans' character status is indeterminate (Vranas 2005). The situationist experiments show that most humans would behave in a morally contemptuous manner in an open list of situations, and also that most humans would behave in a morally commendable manner in an open list of situations. Vranas concludes that, with respect to their overall moral status, most human beings are neither good, bad, nor intermediate; instead, most humans are morally indeterminate. Most human beings, that is, lack character status. Vranas suggests that virtue ethicists have several reasons to prefer local evaluations of character since they are empirically supported, they can help us to create situations that bring out the good in people, and they can enable us to gauge our emotional and behavioral responses to other behaviorally fragmented individuals appropriately. 
to ethics. Still, however, a multitude of unanswered questions and unexplored routes of argumentation remain: Is there any viable reconstrual of the situationist findings that would more powerfully sanction the conclusions of Harman and Doris in their initial statements of the situationist critiques? Are there any convincing reasons for the virtue ethicist to endorse local, rather than global, traits of character, as Doris suggests? Does a thorough canvassing of further situationist and non-situationist psychological literature reveal any findings that bear, for better or worse, on virtue ethics?

This volume tracks the situationist debate as it progresses into its third phase, wherein the argumentative and conceptual focus shifts away from the nature of virtue and defending virtue ethics against the Harman-Doris situationist critiques, which primarily characterize the debate's second phase. The contributors to this volume develop responses to many of the questions raised immediately above, follow up on their first or second phase works by developing their earlier arguments or responding to objections to their earlier arguments, or pursue other new paths of argumentation suggested by the first or second phases of the situationist debate.

Contributors to the first section of this volume submit an extensive supply of psychological findings, both situationist and non-situationist, that yields both boons and banes for virtue ethics. J. Prinz defends the controversial situationist critiques lodged by Harman and Doris against their many objectors but, then, proceeds to argue that examining a broader range of psychological findings empirically establishes the existence of global traits of character. Good evidence exists, Prinz argues, that human beings' self-conceptions, political attitudes, and national origins exhibit the stable mental roots and yield the inter-situational consistency of behavior sufficient for thinking of them as global character traits. Ironically, however, the existence of global character traits does not save virtue ethics. Appealing to an extensive look at the cultural variance of virtues, Prinz argues that no list of virtues does or could possess a univocal nature necessary for the virtues to carry any normative force. There are global traits of character, but virtue ethics lacks normativity; virtue ethics is, hence, not a distinct alternative to rule-based approaches to ethics.

Miller focuses on Doris's arguments that the situationist findings do not establish the widespread existence of global traits of character. Careful examination of a different body of psychological literature, dealing with subjects' positive and negative moods rather than the situation subjects inhabit, suggests the widespread existence of what Miller calls global helping traits. Global helping traits are similar to global character traits insofar as they ground the truth of counterfactual conditionals concerning human beings' behavior in different kinds of situation and, hence, license predictions of inter-situational consistency and intra-situational stability. Unfortunately, Miller argues, the existence of global helping traits does not vindicate virtue ethics against the situationist critiques, since the efficacy of global helping traits rests upon subjects' being in a certain mood, while the traditionallyconceived trait of compassion should operate independent of mood. Further study on empathy might, he suggests, help humans to develop empathy-based global helping traits, whose appropriate motivational base would be sufficient for classifying these helping traits as virtues. 
The second section concerns situationism and its implications for the nature of character and virtue ethics. C. Upton defends a local account of character traits. Doris, in his second phase work, argues that virtue ethicists should embrace local character traits since they are empirically adequate and since their adoption can enable moral agents to improve upon their attitudinal responses, reasoning, choices, and behavior. Upton objects, however, that Doris's local traits do not merit classification as traits of character, that Doris fails to establish that trait ascriptions are necessary for establishing the boons which local trait ascriptions are supposed to enable us to achieve, and that Doris's local traits' justification is wholly dependent upon the empirical situation, which holds only contingently. Upton proceeds to defend local traits of character on the basis of their abilities accurately to appraise moral agents and to retain the normative integrity of the concept of justice; the local traits that result are theoretically related to global traits of character, their ascription is not expendable, and their justification is not contingent.

Sreenivasan begins by defending his second phase challenge to the situationist critiques by responding to some recent objections (Sreenivasan 2002, and Webber 2006). Webber argues, first, that Sreenivasan examines only one situationist experiment, namely, the Hartshorne and May honesty experiment, but that this experiment does not adequately represent the body of situationist findings and, second, that Sreenivasan's challenge to the situationist critiques trades on two different senses of what it is for a trait to exhibit cross-situational consistency. After defending his second phase arguments against the situationist critiques, Sreenivasan proceeds to develop a novel argument against the traditional virtue ethical thesis that the virtues are unified.

Vranas argues for the epistemic thesis that most human beings' character status is indeterminate. Vranas's second phase work argued for the metaphysical facet of this thesis but, here, he argues that not only are we actually indeterminate with respect to our overall character status, but that we know that we are so indeterminate.

Contributors to the third section revisit situationism and the situationist critiques of virtue ethics, refining and extending their earlier arguments, and deriving further implications for virtue ethics as a whole. Harman defends his version of the situationist critique. He argues that, while the findings of social psychology do not demonstrate that virtue ethics is not empirically adequate, they ought properly to undermine one's confidence in the existence of such traits. He concludes that the virtues are reasonably conceived as fleeting features of acts rather than stable features of moral agents.

Kupperman extends his phase two work on situationism and argues that the virtues are conceptually complex, allowing for exceptions and improvement and that the virtues are, hence, compatible with situationist findings. Kupperman draws the two conclusions that virtue-based reasoning does not necessarily preclude the kind of reasoning typified by Utilitarians and Kantians, and that sophisticated virtueethical reasoning should begin with local traits of character and proceed to generalities about virtue, rather than vice versa.

Finally, Badhwar argues that global virtue is psychologically impossible, given the myriad practical, emotional, and cognitive obstacles that impede its development. Badhwar appeals to her earlier arguments for the domain-specificity of virtue 
to conclude that, while local traits permeate the human moral-psychological structure, we should not try to understand ourselves as a causally, emotionally, and psychologically disparate aggregate of situation-specific local traits. Badhwar concludes by suggesting that non-situational factors, in particular, findings on learned helplessness ought to be incorporated into a complete understanding of why Milgram's subjects behaved as deplorably as they did.

Acknowledgements I am grateful to the University of Denver, the University of Denver Department of Philosophy, and the Carl M. Williams Institute of Ethics and Values for providing the support that made this collection possible. Special thanks to Naomi Reshotko and John Doris. Thanks also to Bertha Alvarez, Neera Badhwar, Jennifer Baker, Lorraine Besser-Jones, Robert Card, Antonio Chu, Stephen Ellis, Julia Driver, Gilbert Harman, Rachana Kamtekar, Joshua Knobe, Joel Kupperman, Jennifer McKitrick, Maria Merritt, Christian Miller, Jesse Prinz, Erica Roedder, Nancy Snow, Gopal Sreenivasan, James Taylor, Chris Tucker, Peter Vranas and Jennifer Wright.

\section{References}

Annas, J. 2003. Virtue ethics and social psychology. A Priori 2: 20-33.

Aristotle. 1985. Nicomachean ethics. (trans: Terence Irwin). Indianapolis: Hackett Publishing Company. Athanassoulis, N. 1999. A response to Harman: Virtue ethics and character traits. Proceedings of the Aristotelian society vol. c:215-221.

Badhwar, N. 1996. The Limited unity of virtue. Nous 30: 306-329.

Blackburn, S. 1998. Ruling passions: A theory of practical reasoning. Oxford: Clarendon Press.

Blass, T. 1996. Attribution of responsibility and trust in the Milgram obedience experiment. Journal of Applied Social Psychology 26: 1529-1535.

Blass, T. 2004. The Man who shocked the world: The life and legacy of Stanley Milgram. New York: Basic Books.

Cunningham, M. 1979. Weather, mood, and helping behavior: Quasi experiments with the sunshine samaritan. Journal of Personality and Social Psychology 37: 1947-1956.

Darley, J. 1995. Constructive and destructive obedience: A Taxonomy of principal-agent relationships. Journal of Social Issues 51: 125-154.

Darley, J., and C. Batson. 1973. From Jerusalem to Jericho: A study of situational and dispositional variables in helping behavior. Journal of Personality and Social Psychology 27: 100-118.

DePaul, M. 2000. Character, traits, virtues, and vices: Are there none? In Proceedings of the 20th World Congress of Philosophy, ed. B. Elevitch, v. 9 Philosophy of Mind, 141-157. Bowling Green: Philosophy Documentation Center.

Doris, J. 1998. Persons, situations, and virtue ethics. Nous 32: 504-530.

Doris, J. 2002. Lack of character: Personality and moral behavior. Cambridge: Cambridge University Press.

Doris, J., and D. Murphy. 2007. From My Lai to Abu Ghraib: The Moral psychology of atrocity. Midwest Studies in Philosophy 31: 25-55.

Elms, A. 1995. Obedience in retrospect. Journal of Social Issues 51: 21-31.

Flanagan, O. 1991. Varieties of moral personality. Cambridge: Harvard University Press.

Gelfand, D., D. Hartman, P. Walder, and B. Page. 1973. Who reports shoplifters? A field-experimental study. Journal of Personality and Social Psychology 25: 276-285.

Goldhagen, D. 1996. Hitler's willing executioners: Ordinary Germans and the Holocaust. New York: Knopf.

Haney, C., W. Banks, and P. Zimbardo. 1973. Interpersonal dynamics of a simulated prison. International Journal of Criminology and Penology 1: 69-97.

Haney, C., and P. Zimbardo. 1998. The Past and future of U.S. prison policy: Twenty-five years after the Stanford prison experiment. American Psychologist 53: 709-727.

Harman, G. 1999. Moral philosophy meets social psychology: Virtue ethics and the fundamental attribution error. In Proceedings of the Aristotelian society 99: 315-331. 
Harman, G. 2000. The Nonexistence of character traits. In Proceedings of the Aristotelian society 100: 223-226.

Hartshorne, H., and M. May. 1982. Studies in the nature of character, v. I: Studies in deceit. New York: Macmillan.

Hurka, H. 2001. Virtue, vice, and value. Oxford: Oxford University Press.

Kamtekar, R. 2004. Situationism and virtue ethics on the content of our character. Ethics 114: 458-491.

Kupperman, J. 1991. Character. Oxford: Oxford University Press.

Kupperman, J. 2001. The indispensability of character. Philosophy 76: 239-250.

Lutsky, N. 1995. When is "obedience" obedience? Conceptual and historical commentary. Journal of Social Issues 51: 55-65.

Mathews, K., and L. Cannon. 1975. Environmental noise level as a determinant of helping behavior. Journal of Personality and Social Psychology 32: 571-577.

Meeus, W., and Q. Raaijmakers. 1995. Obedience in modern society: The Utrecht studies. Journal of Social Issues 51: 155-175.

Merritt, M. 2000. Virtue ethics and situationist personality psychology. Ethical Theory and Moral Practice 3: 365-383.

Milgram, S. 1963. Behavioral study of obedience. Journal of Abnormal and Social Psychology 67: 371-378.

Milgram, S. 1974. Obedience to authority. New York: Harper and Row.

Miller, A. 1995. Constructions of the obedience experiments: A focus upon domains of relevance. Journal of Social Issues 51: 33-53.

Miller, C. 2003. Social psychology and virtue ethics. The Journal of Ethics 7: 367-395.

Modigliani, A., and F. Rochat. 1995. The Role of interaction sequences and the timing of resistance in shaping obedience and defiance to authority. Journal of Social Issues 51: 107-123.

Railton, P. 1997. Made in the shade: Moral compatibilism and the aims of moral theory. Canadian Journal of Philosophy Supplementary Volume 21: 79-106.

Rochat, F., and A. Modigliani. 1995. The Ordinary quality of resistance: From Milgram's laboratory to the village of Le Chambon. Journal of Social Issues 51: 195-210.

Rosenthal, A. 1999. Thirty-eight witnesses: The Kitty Genevese case, 2nd ed. Berkeley: University of California Press.

Ross, L., and R. Nisbett. 1991. The person and the situation. Philadelphia: Temple University Press.

Sabini, J., and M. Silver. 2005. Lack of character? Situationism critiqued. Ethics 115: 535-562.

Shaffer, D., M. Rogel, and C. Hendrick. 1975. Intervention in the library: The effect of increased responsibility on bystanders' willingness to prevent a theft. Journal of Applied Social Psychology 5: 303-319.

Sreenivasan, G. 2002. Errors about errors: Virtue theory and trait attribution. Mind 111: 47-68.

Swanton, C. 2003. Virtue ethics. Oxford: Oxford University Press.

Vranas, P. 2005. The Indeterminacy paradox: Character evaluations and human psychology. Nous 39: $1-42$.

Webber, J. 2006. Character, consistency, and classification. Mind 115: 651-658.

Zimbardo, P. 2007. The Lucifer effect: Understanding how good people turn evil. Random House Trade Paperbacks. 